\title{
Pengaruh Penambahan Berbagai Komposisi Bahan Organik Terhadap Karakteristik Hidroton Sebagai Media Tanam
}

\section{The Effect of Addition Various Composition of Organic Materials on The Characteristics of Hydroton As A Growth Media}

\author{
Ade Sylvia Rosman ${ }^{1}$, Dwi Rustam Kendarto ${ }^{2}$, Sophia Dwiratna ${ }^{2 *}$ \\ ${ }^{1}$ Program Studi Teknik Pertanian, Fakultas Teknologi Industri Pertanian, Universitas Padjadjaran. \\ ${ }^{2}$ Departemen Teknik Pertanian dan Biosistem, Fakultas Teknologi Industri Pertanian, Universitas \\ Padjadjaran. Jl. Raya Bandung-Sumedang km 21 Jatinangor 43563 \\ *Corresponding author: sophia.dwiratna@unpad.ac.id
}

\begin{abstract}
Growth media is one of the most important factors in crop cultivation. A good growth medium must be able to meet the characteristic requirements as growth media. Hydroton is an anorganic growth medium from heated clay soil. Clay in holding water is influenced by soil texture and organic matter. The addition of organic material to the hydroton can change the physical characteristics of the hydroton. This study aims to determine the effect and the best composition of the addition of organic matter in the form of compost, husk charcoal and cocopeat in different doses on the characteristics of hydroton as a hydroponic growth medium. The experiment was arranged using a Completely Randomized Design (CRD) with eight treatments in the form of control and addition of each organic material with a dose of $2.5 \%$ and $5 \%$ for four replications. Data were analyzed using ANOVA and continued with DMRT test at the level of 5\%. The results showed that the addition of organic matter significantly affected the valueof bulk density, water content, whc, hydroton hardness level, $\mathrm{pH}$ and EC. The treatment that is considered to give the best results is found in the D5 treatment (Cocopeat $5 \%$ ) with bulk density media values $1,417 \mathrm{gr} / \mathrm{cm}^{3}$, water content $3,623 \%$, hardness $38 \mathrm{~N} / \mathrm{cm}^{2}$, water holding capacity 37,453\%, pH 6,175, and EC 192,05 $\mu \mathrm{S} / \mathrm{cm}$.
\end{abstract}

Keywords: Growth media, organic matter, clay soil, hydroton, hydroponics

\begin{abstract}
ABSTRAK
Media tanam adalah salah satu faktor penting dalam budidaya tanam. Media tanam yang baik harus mampu memenuhi persyaratan karakteristik sebagai media tanam. Hidroton merupakan media tanam anorganik dari tanah liat yang dipanaskan. Tanah liat dalam menahan air dipengaruhi oleh tekstur tanah dan bahan organik. Penambahan bahan organik pada hidroton dapat mengubah karakteristik hidroton. Penelitian ini bertujuan untuk mengetahui pengaruh dan komposisi terbaik penambahan bahan organik berupa arang sekam, cocopeat dan kompos pada pembuatan hidroton terhadap karakteristik hidroton sebagai media tanam hidroponik. Percobaan disusun menggunakan Rancangan Acak Lengkap (RAL) dengan delapan perlakuan berupa kontrol dan penambahan masing-masing bahan organik dengan dosis sebesar 2,5\% dan 5\% sebanyak empat kali ulangan. Data dianalisis menggunakan ANOVA dan dilanjutkan dengan uji DMRT pada taraf 5\%. Hasil penelitian menunjukkan bahwa penambahan bahan organik berpengaruh nyata terhadap nilai bobot isi, kadar air, tingkat kekerasan, water holding capacity (WHC), $\mathrm{pH}$ dan nilai EC hidroton. Perlakuan yang dianggap memberikan hasil terbaik terdapat pada perlakuan D5 (Cocopeat 5\%) dengan nilai BD media 1,417 gr/ $\mathrm{cm}^{3}$, kadar air 3,623\%, kekerasan 38,001 N/cm ${ }^{2}$, WHC 37,453\%, pH 6,175, dan EC $192,05 \mu \mathrm{S} / \mathrm{cm}$.
\end{abstract}

Kata Kunci: Media tanam, bahan organik, tanah liat, hidroton, hidroponik 


\section{PENDAHULUAN}

Media tanam adalah salah satu faktor penting yang sangat mempengaruhi produktivitas pertumbuhan tanaman. Menurut Sutanto (2002) karakteristik media tanam hidroponik yang baik adalah media tanam harus dapat menyerap dan menghantar air, tidak mempengaruhi $\mathrm{pH}$ air, tidak berubah warna, dan tidak mudah lapuk atau busuk, selain itu media tanam juga harus berfungsi sebagai pegangan akar dan perantara larutan nutrisi. Terdapat media dari tanah liat yang dibentuk bulat dan dipanaskan pada suhu tinggi yang dikenal sebagai media hidroton di kalangan petani sistem hidroponik Jerman. Berbagai keunggulan hidroton antara lain drainase yang baik dalam membuang kelebihan air (over watering) tetapi tetap menyimpan nutrisi yang cukup bagi akar, steril, $\mathrm{pH}$ netral, aerasi baik, mudah dipanen dan transplantasi, ramah lingkungan dan dapat digunakan berulang kali sehingga menghemat biaya produksi (Kevin, 2016).

Intara dkk (2011) menyatakan kemampuan tanah dalam menahan air dipengaruhi oleh tekstur tanah dan bahan organik. Tanah liat sebagai bahan baku hidroton memiliki kemampuan mengikat air yang baik karena sebagian besar dari teksturnya tersusun atas pori mikro. Djajakirana (2002) juga mengungkapkan bahan organik memiliki peran dan fungsi yang sangat vital di dalam tanah, ia berperan sangat penting dalam mempengaruhi ketiga sifat tanah.

Penambahan bahan organik pada media tanam hidroton diduga dapat memperbaiki karakteristik fisik, biologis dan kimia pada media tanam tersebut. Intara dkk (2011) menambahkan bahwa pemberian bahan organik berupa pupuk kandang dan kompos pada tanah bertekstur liat dapat meningkatkan kadar air tanah dan kapasitas air tersedia (WHC) serta mengurangi evaporasi dan berat volume tanah. Berkaitan dengan hal tersebut Oktafri dkk (2015) dalam penelitiannya menghasilkan kesimpulan bahwa penambahan digestate dalam pencampur hidroton dapat meningkatkan nilai daya serap air media hidroton dibandingkan hanya menggunakan bahan baku tanah liat saja. Komposisi digestate berpengaruh nyata terhadap BD partikel, BD media, daya serap air, dan kekerasan hidroton, serta berat brangkasan tanaman selada. Dwiratna \& Suryadi (2017) menambahkan melalui penelitiannya bahwa pemberian dosis pupuk organik dapat menurunkan bobot isi tanah sebesar $15,57 \%$, serta meningkatkan $10,38 \%$ kadar air tanah, $12,97 \%$ porositas tanah dan $49,77 \%$ permeabilitas tanah.

Bahan organik yang dapat digunakan sebagai pencampur media tanah bisa berasal dari limbah organik pertanian seperti arang sekam, cocopeat dan kompos. Arang sekam, cocopeat dan kompos sebagai tambahan bahan organik memiliki kemampuan dalam membantu mengikat butiran liat membentuk ikatan butiran yang lebih besar, sehingga dapat memperbesar ruang-ruang udara diantara ikatan butiran sehingga sirkulasi udara lancar (P, Munkholm, S. Elmholt, \& Olesen, 2007).

Media hidroton yang baik harus dapat memenuhi sayarat-syarat media tanam, oleh karena itu untuk menghasilkan hidroton yang memenuhi syarat media tanam perlu dianalisis tentang pengaruh penambahan bahan organik terhadap karakteristik hidroton sebagai media tanam melalui beberapa parameter pengujian yaitu bobot isi, tingkat kekerasan, water holding capacity (WHC), pH dan nilai EC. Tujuan penelitian ini adalah untuk mengetahui pengaruh penambahan bahan organik berupa arang sekam, cocopeat dan kompos pada hidroton serta komposisi campuran media yang paling tepat untuk menghasilkan karakteristik hidroton yang paling optimal sebagai media tanam hidroponik.

\section{BAHAN DAN METODE}

Penelitian dilaksanakan pada bulan Janari sampai Maret 2019. Pembuatan media hidroton, pengujian sampel serta analisis data dilakukan di Laboratorium Sumber Daya Air, Departemen Teknik Pertanian dan Biosistem, Fakultas Teknologi Industri Pertanian, Universitas Padjadjaran. Pembakaran media hidroton dilakukan di Toko Tembikar Elina Keramik, Bandung.

Alat-alat yang digunakan adalah alat tulis, cangkul, cawan, desikator, EC meter, ember, gelas ukur, kamera, laptop dengan software SPSS, nampan, oven, saringan, $\mathrm{pH}$ meter, pocket 
penetrometer, tanur dan timbangan. Bahanbahan yang digunakan adalah air, akuades, arang sekam, cocopeat, kompos, tanah liat.

Penelitian ini menggunakan metode Rancangan Acak Lengkap (RAL) non faktorial. Penelitian ini terdiri dari 8 perlakuan dengan 4 kali pengulangan sehingga terdapat 32 kombinasi perlakuan. Kombinasi perlakuan yang akan digunakan dalam penelitian adalah sebagai berikut: D0 (Hidroton Asli (Hidroton curah dibeli di pasaran)); D1 (Bahan organik 0\%); D2 (Arang Sekam 2,5\%); D3 (Arang Sekam 5\%); D4 (Cocopeat 2,5\%); D5 (Cocopeat 5\%); D6 (Kompos 2,5\%); D7 (Kompos 5\%).

Pembuatan media hidroton dilakukan secara manual menggunakan tangan dengan mencampurkan bahan baku yaitu tanah liat dengan bahan organik. Besar komposisi bahan organik yang digunakan sebagai perlakuan yaitu $0 \%, 2,5 \%$, dan $5 \%$ dari berat tanah liat. Pembuatan media hidroton meliputi penyiapan tanah liat yang telah dihaluskan dan dikeringkan, kemudian dicampurkan bahan organik berupa arang sekam, cocopeat dan kompos sampai merata serta tambahkan air secukupnya agar dapat dibentuk granul tanah liat. Ukuran pada setiap perlakuan dalam pembuatan hidroton diasumsikan seragam hingga terbentuk granul sebesar 10-12 mm dengan berat 2 gram. Hasil penggranulan kemudian dikeringkan (dijemur). Granul yang sudah kering dibakar menggunakan tanur dengan suhu $\pm 550^{\circ} \mathrm{C}$ selama kurang lebih 2 jam. Selanjutnya dilakukan pengujian hidroton berdasarkan parameter sebagai berikut:

a. Bobot isi

Bobot isi merupakan pengukuran massa kering bahan/media (gr) setiap satuan volume $\left(\mathrm{cm}^{3}\right)$. Pengukuran bobot isi yang dilakukan terbagi menjadi 2, bobot isi partikel (arang sekam, cocopeat, kompos) dan bobot isi media hidroton. Pengujian dilakukan dengan persamaan berikut:

$$
\text { Bobot isi }=\frac{\mathrm{m}}{\mathrm{v}}
$$

b. Masing-masing contoh dimasukkan ke dalam cawan yang telah ditimbang berat kosongnya (W3), kemudian contoh ditimbang untuk mendapatkan berat media sebelum di oven (W1). Selanjutnya contoh dimasukkan ke dalam oven selama 24 jam dengan suhu $(110 \pm 5)^{\circ} \mathrm{C}$ atau sampai berat tetap. Setelah 24 jam, contoh dikeluarkan dari oven kemudian didinginkan di dalam desikator. Setelah dingin contoh kemudian ditimbang (W2). Kadar air (KA) dihitung dengan rumus :

$$
\text { \% Kadar Air }=\frac{\mathrm{W} 1-\mathrm{W} 2}{\mathrm{~W} 2-\mathrm{W} 3} \times 100 \%
$$

c. Tingkat Kekerasan

Pengujian kekerasan media hidroton dilakukan dengan menggunakan penetrometer saku. Nilai pengukuran dibaca melalui cincin gesekan pada laras piston.

d. Water holding capacity (WHC)

Uji daya serap air bertujuan untuk mengetahui batas kemampuan maksimum media dalam menyimpan air. Pengukuran daya serap air dilakukan dengan merendam media selama \pm 24 jam kemudian ditiriskan sampai tidak ada lagi air yang menetes atau keadaan field capacity (B1). Media tersebut kemudian dikeringkan dengan oven pada suhu $105^{\circ} \mathrm{C}$ selama \pm 24 jam (B2). Nilai WHC dihitung dengan persamaan berikut:

$$
\mathrm{WHC}=\frac{\mathrm{B} 1-\mathrm{B} 2}{\mathrm{~B} 2} \times 100 \%
$$

e. $\mathrm{pH}$ dan Ec

Pengukuran nilai $\mathrm{pH}$ mengikuti yang dilakukan oleh Awang dkk (2009). Bahan media tanam hidroton sebanyak $10 \mathrm{gr}$ media diambil, ditambahkan $50 \mathrm{ml}$ aquades, dihomogenkan dan selanjutnya dibiarkan selama 24 jam. Nilai larutan sampel media kemudian diukur dengan $\mathrm{pH}$ meter. Pengukuran EC media tanam dilakukan dengan cara mengambil bahan media sebanyak 40 gr, dicampur dengan 80 $\mathrm{ml}$ aquades, dihomogenkan, dan dibiarkan selama 60 menit. Nilai EC larutan sampel media kemudian diukur dengan EC meter.

\section{HASIL DAN PEMBAHASAN}

\section{Analisis Sifat Fisik Tanah}

Pengujian sifat fisik tanah dilakukan untuk mengetahui kondisi tanah yang digunakan sebagai bahan awal pembuatan media tanam hidroton. Bahan baku tanah liat yang digunakan dalam penelitian ini merupakan tanah inceptisol 
yang berasal dari lahan Ciparanje, Jatinangor. Hasil analisis tekstur tanah menunjukkan bahwa tanah yang digunakan memiliki tekstur liat, dengan persentase perbandingan fraksi pasir $4 \%$, debu $28 \%$, dan liat $68 \%$, sedangkan data analisis sifat fisik tanah yang digunakan pada pembuatan media hidroton dirangkum dalam Tabel 1.

Tabel 1. Hasil analisis sifat fisik bahan baku tanah

\begin{tabular}{lccc}
\hline Parameter & $\begin{array}{c}\text { Satuan } \\
\left(\mathrm{g} / \mathrm{cm}^{3}\right)\end{array}$ & $\begin{array}{c}\text { Hasil } \\
\text { Bobot Isi }\end{array}$ & $\begin{array}{c}\text { Kriteria } \\
\text { Rendah }\end{array}$ \\
\hline Kadar Air & $(\%)$ & 40,90 & - \\
\hline Porositas & $(\%)$ & 56,23 & Baik \\
\hline Struktur & - & - & $\begin{array}{c}\text { Subangular } \\
\text { Blocky }\end{array}$ \\
\hline Tekstur & - & Liat & - \\
\hline
\end{tabular}

\section{Hidroton}

Hasil pembakaran menghasilkan hidroton dengan tekstur yang lebih keras dibandingkan sebelum dibakar. Efek pembakaran tanah liat menjadi hidroton memberikan perubahan fisik terhadap warna dan kekerasan. Menurut Astuti (1997) tanah liat yang dibakar pada suhu berkisar antara $500-800^{\circ} \mathrm{C}$ akan menggelas, selain itu dapat menghilangkan uap air yang terikat pada molekul tanah liat, serta membakar habis unsur karbon dan bahan organik.

Media hidroton yang ditambahkan bahanbahan organik menghasilkan warna merah bata yang lebih gelap dengan warna sedikit kehitaman di permukaan hasil terbakarnya sisa bahan organik yang tidak tercampur merata serta terbentuk rongga-rongga kecil di permukaan seperti pada Gambar 1. Campuran bahan organik berupa cocopeat menghasilkan warna merah lebih terang dibandingkan arang sekam yang berwarna lebih muda, sedangkan kompos menghasilkan warna paling gelap dan tidak merata. Oktafri et al., (2015) menyatakan warna kehitaman pada hidroton diduga disebabkan karena peletakan hidroton ditumpukan paling bawah saat proses pembakaran.

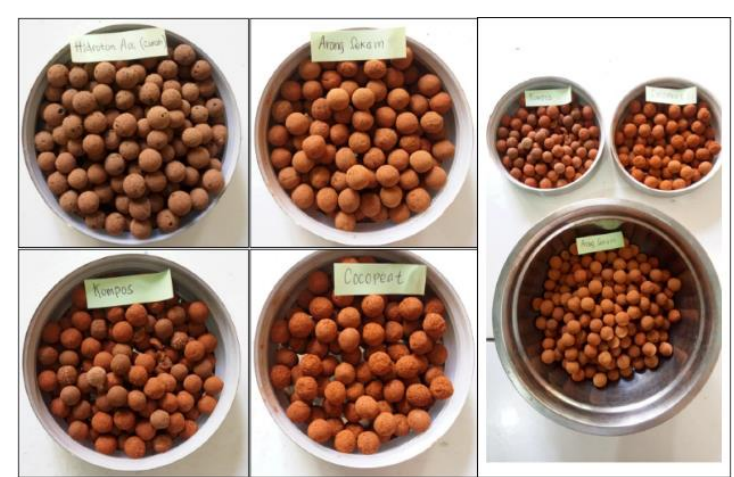

Gambar 1. Produk Media Hidroton

\section{Parameter Pengujian Media Hidroton}

Analisis ragam (ANOVA) menunjukkan bahwa terdapat perbedaan nyata antara perlakuan komposisi campuran bahan organik yang diberikan terhadap semua parameter pengujian karakteristik hidroton antara lain bobot isi, kadar air, tingkat kekerasan, water holding capacity (WHC), $\mathrm{pH}$ dan nilai EC seperti yang dirangkum dalam Tabel 2.

Tabel 2. Hasil pengujian berbagai parameter terhadap karakteristik media hidroton.

\begin{tabular}{|c|c|c|c|c|c|c|}
\hline Perlakuan & $\begin{array}{c}\text { Bobot } \\
\text { isi } \\
\left(\mathrm{gr} / \mathrm{cm}^{3}\right)\end{array}$ & $\begin{array}{c}\text { Kadar } \\
\text { Air } \\
(\%)\end{array}$ & $\begin{array}{c}\text { Tingkat } \\
\text { Kekerasan } \\
\left(\mathrm{N} / \mathrm{cm}^{2}\right)\end{array}$ & $\begin{array}{c}\text { WHC } \\
(\%)\end{array}$ & $\begin{array}{c}\text { EC } \\
(\mu \mathrm{S} / \mathrm{cm})\end{array}$ & pH \\
\hline D0 (Hidroton Asli) & $0,907 \mathrm{a}$ & $0,801 \mathrm{a}$ & $37,878 \mathrm{a}$ & $20,956 a$ & $136,850 \mathrm{a}$ & $6,525 d$ \\
\hline D1 (Bahan Organik 0\%) & $1,489 f$ & $1,563 \mathrm{ab}$ & $39,840 \mathrm{bcd}$ & $28,668 b$ & $137,675 a$ & $6,00 \mathrm{abc}$ \\
\hline D2 (Arang Sekam 2,5\%) & $1,464 \mathrm{de}$ & $2,186 a b c$ & $39,472 \mathrm{abc}$ & $33,195 \mathrm{c}$ & $181,650 \mathrm{c}$ & $6,05 \mathrm{bc}$ \\
\hline D3 (Arang Sekam 5\%) & $1,45 \mathrm{cde}$ & $1,627 \mathrm{ab}$ & $38,981 \mathrm{ab}$ & $34,332 \mathrm{c}$ & $152,875 b$ & $6,20 \mathrm{~d}$ \\
\hline D4 (Cocopeat 2,5\%) & $1,372 b$ & $1,348 \mathrm{ab}$ & $38,369 \mathrm{ab}$ & $33,271 \mathrm{c}$ & $190,150 \mathrm{c}$ & $6,075 \mathrm{bc}$ \\
\hline D5 (Cocopeat 5\%) & $1,417 \mathrm{c}$ & $3,623 c$ & $38,001 \mathrm{a}$ & $37,453 \mathrm{~d}$ & $192,050 \mathrm{c}$ & $6,175 \mathrm{~cd}$ \\
\hline D6 (Kompos 2,5\%) & 1,470de & $1,214 \mathrm{ab}$ & $41,065 \mathrm{~cd}$ & $22,495 a$ & $194,000 \mathrm{c}$ & $5,675 \mathrm{a}$ \\
\hline D7 (Kompos 5\%) & $1,432 \mathrm{~cd}$ & $2,736 b c$ & $41,188 d$ & $28,405 b$ & $196,988 \mathrm{c}$ & $5,75 \mathrm{ab}$ \\
\hline
\end{tabular}

Keterangan : Nilai Rata-rata perlakuan yang ditandai dengan huruf yang sama tidak berbeda nyata menurut uji Duncan taraf $5 \%$ 


\section{a. Bobot isi (Bulk Density)}

Bobot isi menunjukkan bobot media hidroton kering per satuan volume media. Pada penelitian ini dilakukan pengukuran BD media hidroton dan BD bahan organik arang sekam, cocopeat dan kompos. Hasil pengujian bobot isi partikel bahan organik terlihat pada Tabel 3 menunjukkan nilai tertinggi untuk kompos yaitu $0,75 \mathrm{gr} / \mathrm{cm}^{3}$ diikuti arang sekam $0,511 \mathrm{gr} / \mathrm{cm}^{3}$ dan cocopeat $0,255 \mathrm{gr} / \mathrm{cm}^{3}$.

Tabel 3. Hasil pengujian Bobot isi partikel bahan organik

\begin{tabular}{lccc} 
Perlakuan & $\begin{array}{c}\text { Massa } \\
\text { Kering } \\
(\mathbf{g r})\end{array}$ & $\begin{array}{c}\text { Volume } \\
\text { Partikel } \\
\left(\mathbf{c m}^{\mathbf{3}}\right)\end{array}$ & $\begin{array}{c}\text { BD } \\
\text { Partikel } \\
\left(\mathbf{g r}_{\mathbf{c}} \mathbf{c m}^{\mathbf{3}}\right)\end{array}$ \\
\hline Arang Sekam & 12 & 23,5 & 0,511 \\
\hline Cocopeat & 12 & 47 & 0,255 \\
\hline Kompos & 12 & 16 & 0,75 \\
\hline
\end{tabular}

Tabel 4. Sidik Ragam Bobot isi

\begin{tabular}{lccccc}
\hline Sumber & DB & JK & KT & Fhit & F.05 \\
\hline Perlakuan & 7 & 1,04 & 0,149 & & \\
Galat & 24 & 0,02 & 0,0008 & 173,2 & 2,42 \\
Total & 31 & 1,06 & & & \\
\hline
\end{tabular}

Hasil analisis sidik ragam perlakuan pemberian bahan organik dengan berbagai komposisi yang diberikan berpengaruh sangat nyata terhadap bobot isi hidroton yang dihasilkan seperti pada Tabel 4 yang ditandai dengan (Fh > F0,05) yaitu 173,2.

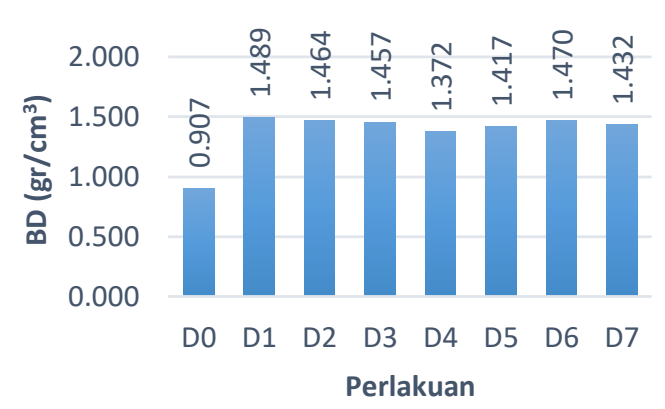

Gambar 2. Nilai Bobot isi Media Hidroton

Hasil pengujian bobot isi media hidroton dapat dilihat pada Gambar 2 yang menunjukkan nilai bobot isi tertinggi terdapat pada perlakuan D1 (Bahan Organik 0\%) yaitu sebesar 1,489 $\mathrm{gr} / \mathrm{cm}^{3}$ dan bobot isi terkecil terdapat pada D0 (Hidroton asli) yaitu sebesar $0,907 \mathrm{gr} / \mathrm{cm}^{3}$. Selanjutnya dilakukan uji lanjutan DMRT untuk mengetahui perbedaan antar rataan taraf perlakuan.
Berdasarkan hasil uji DMRT dengan selang kepercayaan $95 \%$ menghasilkan enam kelas pembagi seperti yang disajikan pada Tabel 2. Analisis menunjukkan semakin tinggi kandungan bahan organik maka nilai bobot isi media semakin rendah. Gambar 2 menunjukkan pula bahwa nilai bobot isi bahan organik berbanding lurus dengan nilai bobot isi media hidroton. Tingkat kerapatan atau bobot isi ini dipengaruhi pula oleh ukuran partikel bahan dimana semakin kecil ukuran partikel bahan maka kerapatan bahan akan semakin tinggi. Hal ini karena semakin kecilnya permukaan sentuh antar partikel suatu media sehingga ruang pori yang terbentuk semakin besar dan besarnya ruang pori akan berpengaruh pada aerasi suatu media, namun faktanya pada pengujian ini bobot isi terendah dihasilkan hidroton asli walaupun penurunan bobot isi terhadap penambahan bahan organik mulai tampak di beberapa perlakuan.

Hardjowigeno (1992) dalam Tyas (2000) menyatakan nilai bobot isi yang semakin besar menunjukkan media tersebut semakin padat dan sulit meneruskan air atau ditembus oleh akar tanaman. Semakin ringan dan padat media tumbuh, maka semakin mudah dan murah pengangkutannya. Selain itu media tanam yang baik perlu memiliki aerasi yang baik pula seperti yang dijelaskan Islami \& Utomo (1995) aerasi berhubungan dengan kepadatan media, semakin tinggi kepadatan media makapenyebaran oksigen semakin rendah. Semakin ringan berat jenis dari media maka akan tersedia pori-pori yang lebih besar bagi udara maupun air, karena udara yang terkandung dalam pori-pori pada media akan membuat berat jenis media menjadi lebih ringan.

\section{b. KadarAir}

Kadar air merupakan salah satu sifat fisik dari bahan yang menunjukkan banyaknya air yang terkandung di dalam media (Hasriani, Kalsim, \& Sukendro, 2013)

Tabel 5. Sidik Ragam Kadar Air

\begin{tabular}{lccccc}
\hline Sumber & DB & JK & KT & Fhit & F.05 \\
\hline Perlakuan & 7 & 23,6 & 3,38 & & \\
Galat & 24 & 31,6 & 1,31 & 2,56 & 2,42 \\
Total & 31 & 55,3 & & & \\
\hline
\end{tabular}

Hasil analisis sidik ragam perlakuan pemberian bahan organik dengan berbagai 
komposisi yang diberikan berpengaruh nyata terhadap kadar air media hidroton yang dihasilkan seperti pada Tabel 5 yang ditandai dengan $(\mathrm{Fh}>\mathrm{F} 0,05)$ yaitu 2,56 .

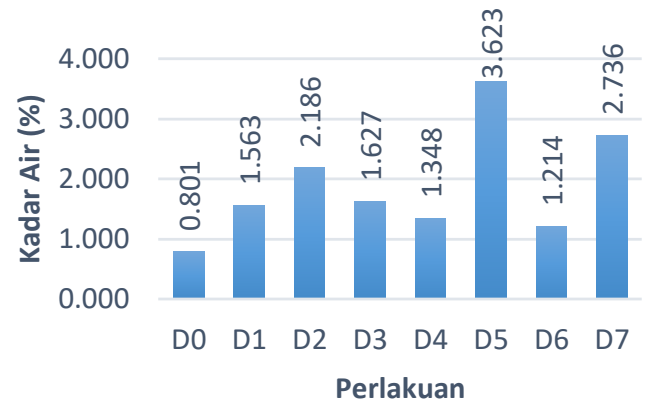

Gambar 3. Nilai Kadar Air Media Hidroton

Hasil pengujian kadar air media hidroton dapat dilihat pada Gambar 3 yang menunjukkan bahwa perlakuan yang menghasilkan kadar air terbesar adalah yang ditambahkan bahan organik cocopeat diikuti arang sekam, kompos dan terakhir hidroton tanpa bahan organik. Persentase nilai kadar air tertinggi terdapat pada perlakuan D5 (cocopeat 5\% yaitu sebesar $3,623 \%$ dan kadar air terkecil terdapat pada D0 (Hidroton asli) yaitu sebesar $0,801 \%$.

Hal ini sesuai dengan pernyataan Istomo (2012) bahwa sifat cocopeat yang memiliki kapasitas menahan air cukup tinggi. Media cocopeat memiliki pori mikro yang mampu menghambat gerakan air lebih besar sehingga menyebabkan ketersediaan air lebih tinggi. Selanjutnya dilakukan uji lanjutan DMRT untuk mengetahui perbedaan antar rataan taraf perlakuan. Berdasarkan hasil uji DMRT dengan selang kepercayaan 95\% menghasilkan tiga kelas pembagi seperti yang disajikan pada Tabel 2 . Analisis menunjukkan kemampuan mengikat air pada media dipengaruhi oleh tekstur dan bahan organik didalamnya. Semakin tinggi dosis bahan organik yang diberikan maka semakin besar kadar air yang disimpan. Tingginya kandungan bahan organik dapat menyebabkan banyaknya air yang dapat disimpan dalam hidroton. Bahan organik yang terdapat di dalam media hidroton diduga mampu menahan air akibat terbentuknya rongga pori pada media. Kadar air berpengaruh pada kemampuan media melawan gaya yang diberikan, semakin tinggi nilai kadar air maka semakin rendah kekuatan tanah dan bobot isinya, sehingga tanah lebih mudah ditembus akar tanaman (Hardjowigeno, 2007).

\section{c. Kekerasan}

Pengukuran tingkat kekerasan dilakukan setelah pembakaran media hidroton dan dilakukan untuk mengetahui kekuatan hidroton. Tabel 6. Sidik Ragam Kekerasan

\begin{tabular}{lccccc}
\hline Sumber & DB & JK & KT & Fhit & F.05 \\
\hline Perlakuan & 7 & 46,64 & 6,66 & & \\
Galat & 24 & 26,44 & 1,10 & 6,04 & 2,42 \\
Total & 31 & 73,08 & & & \\
\hline
\end{tabular}

Hasil analisis sidik ragam perlakuan pemberian bahan organik dengan berbagai komposisi yang diberikan berpengaruh nyata terhadap kekerasan hidroton yang dihasilkan seperti pada Tabel 6 yang ditandai dengan (Fh > F0,05) yaitu 6,04

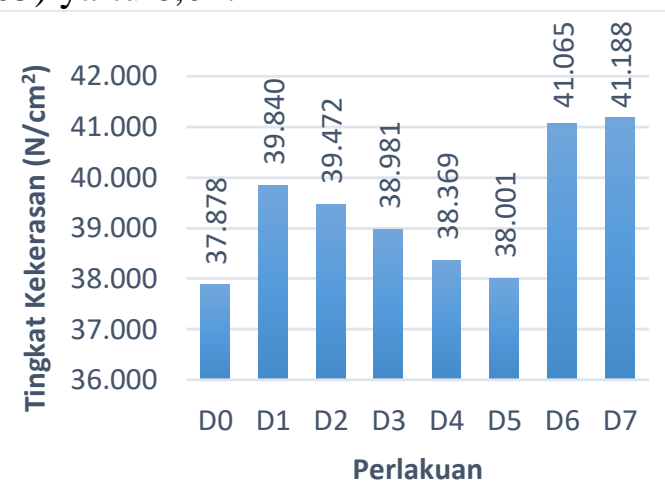

Gambar 4. Tingkat Kekerasan Hidroton

Hasil pengujian whe media hidroton dapat dilihat pada Gambar 4 menunjukkan nilai kekerasan tertinggi terdapat pada perlakuan D7 (kompos 5\%) yaitu sebesar 41,188 N/cm² dan kekerasan terkecil terdapat pada D0 (Hidroton asli) yaitu sebesar $37,878 \mathrm{~N} / \mathrm{cm}^{2}$. Selanjutnya dilakukan uji lanjutan DMRT untuk mengetahui perbedaan antar rataan taraf perlakuan. Berdasarkan hasil uji DMRT dengan selang kepercayaan 95\% menghasilkan empat kelas pembagi seperti yang disajikan pada Tabel 2 . Analisis menunjukkan semakin semakin tinggi penambahan bahan organik pada pembuatan hidroton semakin rendah pula nilai kekerasan yang dihasilkan.

Hal ini sejalan dengan penelitian yang dilakukan Oktafri et al., (2015) yang menyatakan semakin tinggi kandungan digestate pada hidroton, nilai kekerasannya semakin rendah dan bila dikaitkan dengan bobot isi penambahan digestate dapat menurunkan nilai $\mathrm{BD}$ dan kekerasan hidroton, sehingga besarnya nilai kekerasan hidroton sebanding dengan nilai BD 
partikelnya. Tingkat kekerasan akan menentukan umur pakai media namun harus diperhatikan pula semakin keras media tanam akan semakin sulit ditembus akar. Kemampuan media hidroton dalam menahan beban akan menentukan mudah tidaknya media menjadi padat. Penyebab lebih rendahnya tingkat kekerasan perlakuan yang ditambahkan bahan organik adalah karena perlakuan dengan bahan organik diduga memiliki struktur yang lebih lengas dan berpori daripada tanpa bahan organik akibat adanya unsur bahan organik yang terkandung dalam media hidroton.

\section{d. Water Holding Capacity (WHC)}

Salah satu karakteristik media tanam adalah kemampuan dalam menyimpan air. Menurut Islami \& Utomo (1995) materi penyusun dari bahan menentukan proses penyerapan air oleh bahan karena berkaitan dengan rongga yang terdapat pada bahan. Rongga tersebut dapat menampung air yang terserap, dalam hal ini rongga tersebut terdapat didalam media hidroton untuk menyerap air nutrisi dalam sistem hidroponik.

Tabel 7. Sidik Ragam WHC

\begin{tabular}{lccccc}
\hline Sumber & DB & JK & KT & Fhit & F.05 \\
\hline Perlakuan & 7 & 949,8 & 135,7 & & \\
Galat & 24 & 77,05 & 3,21 & 42,2 & 2,42 \\
Total & 31 & 1026,9 & & & \\
\hline
\end{tabular}

Hasil analisis sidik ragam perlakuan pemberian bahan organik dengan berbagai komposisi yang diberikan berpengaruh sangat nyata terhadap WHC hidroton yang dihasilkan seperti pada Tabel 7 yang ditandai dengan (Fh > F0,05) yaitu 42,2.

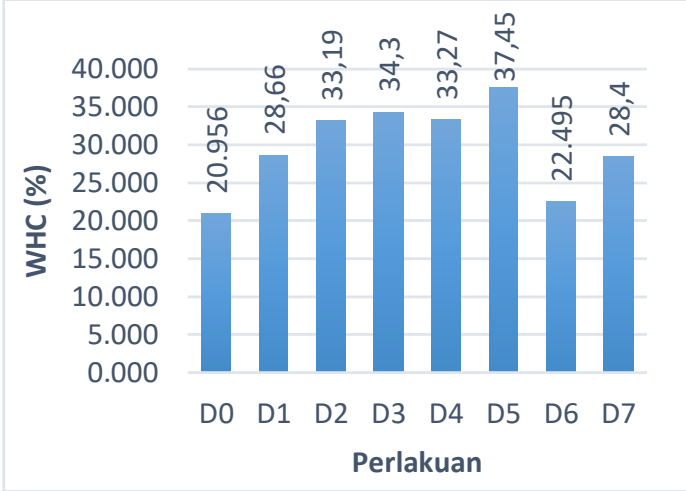

Gambar 5. Nilai Water Holding Capacity (WHC) Media Hidroton
Hasil pengujian whe media hidroton dapat dilihat pada Gambar 5 menunjukkan nilai whc tertinggi terdapat pada perlakuan D5 (cocopeat $5 \%$ ) yaitu sebesar $37,453 \%$ dan whc terkecil terdapat pada D0 (Hidroton asli) yaitu sebesar $20,956 \%$. Selanjutnya dilakukan uji lanjutan DMRT untuk mengetahui perbedaan antar rataan taraf perlakuan. Berdasarkan hasil uji DMRT dengan selang kepercayaan $95 \%$ menghasilkan empat kelas pembagi seperti yang disajikan pada Tabel 2. Hasil analisis menunjukkan semakin banyak bahan organik yang dicampurkan pada pembuatan hidroton maka semakin besar nilai WHC yang dihasilkan seperti yang terlihat pada Gambar 11 dimana dosis 5\% menghasilkan nilai WHC lebih besar dibandingkan 2,5\% dan tanpa bahan organik $(0 \%)$. Media hidroton dengan campuran bahan organik mampu menahan air relatif lebih besar dan berpotensi besar untuk dapat diserap dan dimanfaatkan akar untuk pertumbuhan tanaman.

Hanafiah (2005) menyatakan bahwa menambahkan bahwa bahan organik pada media tanam (tanah) mempunyai pori-pori mikro yang jauh lebih banyak, yang berarti kemampuan media dalam menyimpan air lebih tinggi, sehingga semakin tinggi bahan organik suatu media maka semakin tinggi kemampuan menyimpan airnya. Hal ini dibuktikan dalam penelitian Oktafri dkk (2015) bahwa bahan organik pada proses pembakaran yang membuat rongga pada hidroton serta sisa bahan organik yang tak habis terbakar dapat meningkatkan whc media hidroton karena dapat meningkatkan pori mikro hidroton.

\section{e. pH (Potensial Hidrogen)}

Nilai $\mathrm{pH}$ media tanam akan mempengaruhi daya larut dan ketersediaan nutrisi bagi tanaman karena $\mathrm{pH}$ menentukan mudah tidaknya ion-ion unsur hara diserap oleh tanaman.

Tabel 8. Sidik Ragam $\mathrm{pH}$

\begin{tabular}{lccccc}
\hline Sumber & DB & JK & KT & Fhit & F.05 \\
\hline Perlakuan & 7 & 1,98 & 0,28 & & \\
Galat & 24 & 1,35 & 0,05 & 5,05 & 2,42 \\
Total & 31 & 3,33 & & & \\
\hline
\end{tabular}

Hasil analisis sidik ragam perlakuan pemberian bahan organik dengan berbagai komposisi yang diberikan berpengaruh nyata 
terhadap $\mathrm{pH}$ hidroton yang dihasilkan seperti pada Tabel 8 yang ditandai dengan (Fh > F0,05) yaitu 5,05 .

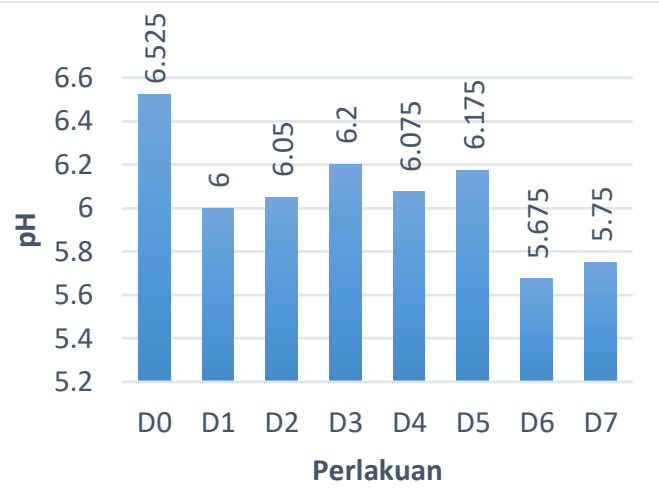

Gambar 6. Nilai pH Media Hidroton

Hasil pengujian $\mathrm{pH}$ media hidroton dapat dilihat pada Gambar 6 menunjukkan nilai $\mathrm{pH}$ tertinggi terdapat pada perlakuan D0 (hidroton asli) yaitu sebesar 6,525 dan $\mathrm{pH}$ terkecil terdapat pada D6 kompos yaitu sebesar 5,675. Selanjutnya dilakukan uji lanjutan DMRT untuk mengetahui perbedaan antar rataan taraf perlakuan. Berdasarkan hasil uji DMRT dengan selang kepercayaan $95 \%$ menghasilkan empat kelas pembagi seperti yang disajikan pada Tabel 2. Syarat media tanam yang baik pada dasarnya memiliki rasio menahan air dan udara yang baik, memiliki pH stabil (antara 5,5-6,5), bisa dibasahi kembali setelah kering (bisa digunakan kembali), tidak cepat rusak, murah, mudah didapat cukup ringan, sehingga tidak menyulitkan transportasi.

Kecenderungan peningkatan $\mathrm{pH}$ akibat pemberian dosis campuran bahan organik pada Gambar 6 menunjukkan bahwa media hidroton dengan campuran bahan organik dosis 5\% memiliki $\mathrm{pH}$ lebih besar daripada media hidroton dengan campuran bahan organik 2,5\%. Suntoro dkk (2001) mengungkapkan bahwa penambahan bahan organik pada tanah masam, antara lain inseptisol, ultisol dan andisol mampu meningkatkan $\mathrm{pH}$ tanah dan mampu menurunkan Al tertukar tanah. Peningkatan $\mathrm{pH}$ tanah terjadi apabila bahan organik yang kita tambahkan telah terdekomposisi lanjut (matang), karena bahan organik yang telah termineralisasi akan melepaskan mineralnya berupa kation-kation basa. Berdasarkan hasil pada Tabel 2, terlihat bahwa hidroton asli (D1) memiliki $\mathrm{pH}$ yang paling mendekati $\mathrm{pH}$ netral $(\mathrm{pH} 7)$ dibandingkan perlakuan lain, namun perlakuan lain masih memiliki nilai $\mathrm{pH}$ yang berada dalam kisaran $\mathrm{pH}$ yang optimal untuk pertumbuhan tanaman.

\section{f. EC (Electrical Conductivity)}

Nilai EC berpengaruh terhadap proses serapan air dan unsur hara oleh akar untuk pertumbuhan tanaman.

Tabel 9. Sidik Ragam Bobot isi

\begin{tabular}{lccccc}
\hline Sumber & DB & JK & KT & Fhit & F. $_{.05}$ \\
\hline Perlakuan & 7 & 18830,2 & 2690 & & \\
Galat & 24 & 2416,8 & 100,7 & 26,7 & 2,42 \\
Total & 31 & 21247.1 & & & \\
\hline
\end{tabular}

Hasil analisis sidik ragam perlakuan pemberian bahan organik dengan berbagai komposisi yang diberikan berpengaruh sangat nyata terhadap $\mathrm{pH}$ hidroton yang dihasilkan seperti pada Tabel 9 yang ditandai dengan (Fh > F0,05) yaitu 26,7.

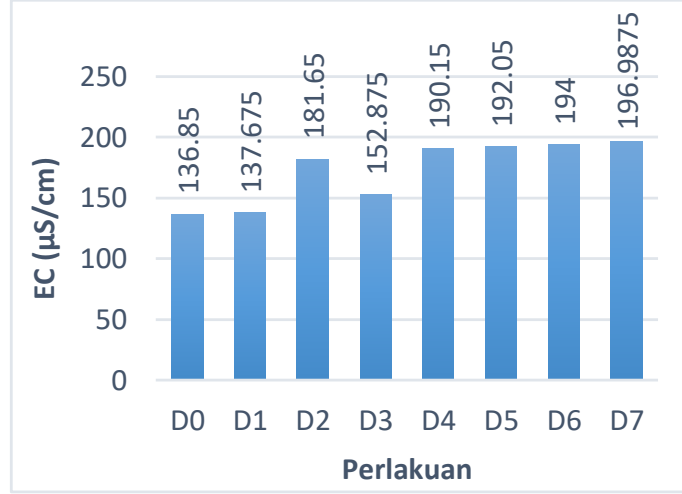

Gambar 7. Nilai EC Media Hidroton

Hasil pengujian EC media hidroton dapat dilihat pada Gambar 7 menunjukkan nilai EC tertinggi terdapat pada perlakuan D7 (kompos $5 \%$ ) yaitu sebesar 196,9875 dan EC terkecil terdapat pada D0 (hidroton asli) yaitu sebesar 136,85. Selanjutnya dilakukan uji lanjutan DMRT untuk mengetahui perbedaan antar rataan taraf perlakuan. Berdasarkan hasil uji DMRT dengan selang kepercayaan $95 \%$ menghasilkan tiga kelas pembagi seperti yang disajikan pada Tabel 2. Berdasarkan Gambar 7 dan Tabel 2 terlihat hubungan naiknya kadar bahan organik yang diberikan terhadap naiknya nilai EC mulai tampak, namun terdapat penyimpangan pada perlakuan D2 dan D3 yaitu arang sekam 2,5\% dan 5\% dimana nilai EC bahan organik 5\% lebih kecil dibandingkan nilai EC bahan organik 2,5\%. Kesimpulan sementara adalah bahwa naiknya kadar bahan organik cenderung menaikkan EC 
media hidroton. Bafdal, Dwiratna, \& Kendarto (2017) juga menyatakkan bahwa nilai EC dipengaruhi pula oleh iklim mikro dalam sistem seperti suhu dan kelembaban serta semakin banyak beberapa ion terlarut, semakin tinggi larutan nutrisi EC.

\subsection{Analisis Perlakuan Terbaik}

Penentuan perlakuan terbaik dilakukan dengan cara menganalisis data hasil parameter pengujian karakteristik hidroton yang telah dilakukan meliputi nilai bobot isi, kadar air, tingkat kekerasan, water holding capacity (WHC), $\mathrm{pH}$ dan nilai EC media hidroton. Hasil analisis menunjukkan perlakuan terbaik terdapat pada perlakuan D5 (cocopeat 5\%) hal ini dapat dilihat dari Tabel 2 yang menunjukkan keunggulan penambahan cocopeat 5\% pada parameter pengujian kadar air dan WHC dimana perlakuan D5 memiliki nilai tertinggi. Hal ini menunjukkan bahwa pada perlakuan D5 media hidroton dapat menyerap dan menyediakan air lebih banyak sebagai media tanam bahkan dibandingkan hidroton asli (D0) yang dijual di pasaran. Sejalan dengan penelitian oleh Bafdal, Dwiratna, \& Kendarto (2018) bahwa penggunaan media arang sekam+cocopeat menghasilkan kadar air tertinggi $73,1 \%$ dan jumlah ruang pori yang paling besar dibandingkan arang sekam+kompos 54,9\% dan arang sekam+humus 59,8\%, dengan kata lain cocopeat dianggap meningkatkan jumlah air yang bisa dipegang oleh media tanam paling optimal.

Perlakuan D5 (Cocopeat 5\%) juga menghasilkan nilai bobot isi dan tingkat kekerasan mendekati nilai perlakuan D0 (hidroton asli) yang memiliki nilai terendah. Tingkat bobot isi dan kekerasan perlakuan D5 (cocopeat 5\%) sudah bisa dikatakan cukup baik karena apabila nilai bobot isi terlalu besar mengakibatkan media semakin padat dan sulit meneruskan air atau ditembus oleh akar tanaman. Semakin ringan dan padat media tumbuh, maka semakin mudah dan murah pengangkutannya. Media tanam yang baik perlu memiliki aerasi yang baik pula. Parameter pengujian $\mathrm{pH}$ media hidroton menunjukkan perlakuan terbaik yang paling mendekati netral adalah D0 (Hidroton asli) dengan nilai $\mathrm{pH}$ 6.525, namun nilai perlakuan D0 tidak jauh berbeda dengan perlakuan D5 (cocopeat 5\%) yaitu 6,175 dimana nilai $\mathrm{pH}$ tersebut masih tergolong optimal bagi media tanam, sedangkan untuk nilai EC tidak berbeda jauh untuk semua perlakuan.

Berdasarkan hasil analisis data hasil pengujian karakteristik media hidroton tersebut menunjukkan bahwa perlakuan cocopeat 5\% merupakan perlakuan terbaik. Hal ini sejalan dengan penelitian Dwi (2019) yang menyatakan pemberian bahan organik berupa cocopeat sebagai campuran pada pembuatan hidroton menghasilkan pertumbuhan dan produktivitas terbaik tanaman pakcoy dari segi fisiologis berupa bobot brangkasan, bobot basah, tinggi tanaman, jumlah daun dan panjang akar dibandingkan pemberian campuran bahan organik berupa arang sekam dan kompos serta hidroton tanpa campuran bahan organik.

\section{SIMPULAN}

Penambahan bahan organik berupa arang sekam, cocopeat dan kompos sebagai campuran pembuatan media tanam hidroton memberikan pengaruh nyata terhadap semua karakteristik media hidroton berupa nilai bobot isi, kadar air, tingkat kekerasan, water holding capacity (WHC), pH dan nilai EC media hidroton. Perlakuan D5 (cocopeat 5\%) memberikan pengaruh paling baik terhadap karakteristik hidroton sebagai media tanam dengan nilai bobot isi sebesar 1,417 gr/ $\mathrm{cm}^{3}$, kadar air 3,623\%, kekerasan 38,001 N/cm ${ }^{2}$, WHC 37,453\%, pH 6,175, dan EC 192, $05 \mu \mathrm{S} / \mathrm{cm}$.

\section{UCAPAN TERIMA KASIH}

Penulis mengucapkan terima kasih kepada Kementrian Riset, Teknologi dan Pendidikan Tinggi Republik Indonesia yang telah mendanai riset ini melalui skema Penelitian Dasar Unggulan Perguruan Tinggi tahun 2018 dengan nomor kontrak 681/UN6.N/LT/2018.

\section{DAFTAR PUSTAKA}

Astuti, A. (1997). Pengetahuan Keramik. Yogyakarta: Gajah Mada University Press. Awang, Y., Shazmi Shaharom, A., B. Mohamad, 
R., \& Ahmad, S. (2009). Chemical and Physical Characteristics of Cocopeat-Based Media Mixtures and Their Effects on the Growth and Development of Celosia cristata. In American Journal of Agricultural and Biological Science (Vol. 4). https://doi.org/10.3844/AJAB.2009.63.71

Bafdal, N., Dwiratna, S., \& Kendarto, D. R. (2017). Impact of water use on paprika (Capsicum annum) by using fertigation and autopot system combined with numerous growing media. Asian Journal of Plant Sciences, 16(3), 149-159. https://doi.org/10.3923/ajps.2017.149.159

Bafdal, N., Dwiratna, S., \& Kendarto, D. R. (2018). Differences Growing Media In Autopot Fertigation System And Its Response To Cherry Tomatoes Yield. Indonesian Journal of Applied Sciences, 7(3), 63-68. https://doi.org/10.24198/ijas.v7i3.14369

Djajakirana. (2002). Pemanfaatan Bahan Organik Untuk Meningkatkan Produktivitas Tanaman. Tanah Dan Iklim, 20, 35-46.

Dwi, T. P. (2019). Pengaruh Karakteristik Hidroton Dengan Berbagai Komposisi Bahan Organik Terhadap Pertumbuhan Dan Produktivitas Tanaman Pakcoy Pada Hidroponik Sistem Rakit Apung. Sumedang. Dwiratna, S., \& Suryadi, E. (2017). Pengaruh Lama Waktu Inkubasi Dan Dosis Pupuk Organik Terhadap Perubahan Sifat Fisik Tanah Inceptisol di Jatinangor. 2(2), 110 116.

Hanafiah, K. A. (2005). Dasar-Dasar Ilmu Tanah (Kedelapan). Jakarta: Raja Grafindo Persada.

Hardjowigeno, S. (2007). Ilmu Tanah. Jakarta: Akademika Pressindo.

Hasriani, Kalsim, D. K., \& Sukendro, A. (2013). Kajian Serbuk Sabut Kelapa (Cocopeat) sebagai Media Tanam. IPB Press, 1-7.

Intara, Y. I., Sapei, A., Erizal, Sembiring, N., \& Djoefrie, M. H. B. (2011). Pengaruh Pemberian Bahan Organik Pada Tanah Liat Dan Lempung Berliat Terhadap Kemampuan Mengikat Air. Jurnal Ilmu Pertanian Indonesia, 16(2), 130-135. Retrieved
http://journal.ipb.ac.id/index.php/JIPI/articl e/view/6457

Islami, T., \& Utomo, W. (1995). Hubungan Tanah, Air Dan Tanaman. Semarang: IKIP Semarang Press.

Istomo, V. N. (2012). Pengaruh perlakuan kombinasi media terhadap pertumbuhan anakan tumih (Combretocarpus rotundatus (Miq.) Danser). Silvikultur Tropika 3, 2, 8184.

Kevin. (2016). Hydroton (Expanded Clay Pebbles) Growing Guide. Retrieved November 5, 2018, from https://www.epicgardening.com/expandedclay-pellets/

Oktafri, Ningsih, Y. A., \& Novita, D. D. (2015). Pembuatan Hidroton Berbagai Ukuran Sebagai Media Tanam Hidroponik Dari Campuran Bahan Baku Tanah Liat Dan Digestate the Making of Hydroton With Different Size As Growth Media. Teknik Pertanian Lampung, 4(4), 267-274.

P, S., Munkholm, L. J., S. Elmholt, J., \& Olesen, E. (2007). Organic Matter and Soil Tilth in Arable Farming: Management Makes A Difference within 5-6 Years. Agriculture, Ecosystems and Environment, 122, 157172.

Suntoro, Syekhfani, Handayanto, E., dan S. (2001). Pengaruh Pemberian Bahan Organik, Dolomit Dan Pupuk K Terhadap Produksi Kacang Tanah (Arachis hypogaea) pada Oxic Dystrundept. Di Jumapolo, Karang anyar, Jawa tengah. A grivita 23 (1), 57-65, 23(1), 57-65.

Sutanto, R. (2002). Penerapan Pertanian Organik. Yogyakarta: Kanisius.

Tyas, S. I. . (2000). Studi Netralisasi Limbah Sabut Kelapa (Cocopeat) sebagai Media Tanam. Bogor. 